\title{
Clinical, Endoscopic and Prognostic Aspects of Primary Gastric Non-Hodgkin's Lymphoma Associated with Acquired Immunodeficiency Syndrome
}

\author{
Rosamar Eulira Fontes Rezende ${ }^{1,2}$, Marcos Mantelmacher ${ }^{1}$, Sandro da Costa Ferreira ${ }^{1}$, Elodie Bomfim Hyppólito ${ }^{2}$, Alcyone Artioli \\ Machado $^{3}$, José Celso Ardengh ${ }^{2}$ and José Luiz Pimenta Módena ${ }^{2}$ \\ ${ }^{I}$ Department of Medicine, Division of Gastroenterology, School of Medicine of Ribeirão Preto, University of São Paulo (FMRP-USP); \\ ${ }^{2}$ Endoscopy Service, School of Medicine of Ribeirão Preto, University of São Paulo (FMRP-USP); ${ }^{3}$ Department of Medicine, Division of \\ Infectious and Tropical Diseases, School of Medicine of Ribeirão Preto, University of São Paulo (FMRP-USP); Ribeirão Preto, SP, Brazil
}

\begin{abstract}
Primary gastric non-Hodgkin's lymphoma (NHL) is a co-morbidity that can be observed during the clinical course of acquired immunodeficiency syndrome (AIDS). We evaluated the prevalence, clinical-evolutive aspects and form of endoscopic presentation of primary gastric NHL associated with AIDS. Two hundred and forty-three HIV patients were submitted to upper digestive endoscopy, with evaluation of clinical, endoscopic and histological data. A CD4 count was made by flow cytometry and viral load was determined in a branched-DNA assay. Six cases (five men; mean age: 37 years; range: 29-46 years) of primary gastric NHL were detected. The median CD4 count was 140 cells/ $\mathrm{mm}^{3}$ and the median viral load was 40,313 copies/mL. Upper digestive endoscopy revealed polypoid (in four patients) ulcero-infiltrative (two patients) and ulcerated (two patients) lesions and combined polypoid and ulcerated lesions (two patients). Histology of the gastric lesions demonstrated B cell NHL (four patients) and T cell NHL (two patients). Five of the six patients died of complications related to gastric NHL. We concluded that primary gastric NHL is an important cause of mortality associated with AIDS.
\end{abstract}

Key-Words: Non-Hodgkin lymphoma, AIDS, stomach, upper digestive endoscopy.

The immunosuppression triggered by acquired immunodeficiency syndrome (AIDS) predisposes to a series of opportunistic infections and neoplasias, such as Kaposi's sarcoma and non-Hodgkin's lymphoma (NHL) [1,2]. Individuals infected with human immunodeficiency virus (HIV) are at high risk to develop NHL; i.e., they are about 50 times more likely to develop NHL than the HIV-negative population $[3,4]$.

NHL is a common complication in the late phase of HIV infection, with a high frequency of involvement of the gastrointestinal tract (GIT) [2,5]. The occurrence of primary GIT NHL has been associated with reduced survival of HIVinfected patients $[3,6]$. Highly active antiretroviral therapy (HAART) seems to have a protective effect against the onset of NHL associated with HIV [4,7].

We evaluated the prevalence of primary gastric NHL in 243 HIV-infected patients submitted to upper digestive endoscopy (UDE) from August 1995 to May 2005 in the Service of Digestive Endoscopy of the Special Unit for the Treatment of Infectious Diseases of the University Hospital, Faculty of Medicine of Ribeirão Preto, to assess the clinicalevolutive aspects and forms of endoscopic presentation of primary gastric NHL associated with AIDS. Clinical data were obtained concerning age, sex, risk factors for HIV acquisition, symptoms related to gastric involvement by NHL, use of HAART, survival time, and mortality data. CD4 counts were

Received on 9 August 2008; revised 3 December 2008.

Address for correspondence: Dr. Rosamar Eulira Fontes Rezende, MD. Departamento de Clínica Médica, Divisão de Gastroenterologia, Faculdade de Medicina de Ribeirão Preto-USP. Av. Bandeirantes, 3900, Monte Alegre. Zip code: 14048-900. Ribeirão Preto-SP-Brazil. Phone: +55 16602 2456. Fax: + 5516633 1144. E-mail: rosamarrezende@uol.com.br.

The Brazilian Journal of Infectious Diseases Publishing. All rights reserved. made by flow cytometry and HIV load was determined by the branched DNA (bDNA) assay six months before the UDE exam. The form of presentation and the location of NHL in the stomach were determined by videogastroscopy [Pentax Model EG 2901 (9.8 mm)].

Fragments of the gastric lesions obtained by endoscopy were evaluated by two experienced pathologists of the service. The material was stained with hematoxylin-eosin and examined by immunohistochemistry with markers for B and T cells. Primary gastric NHL was detected in six of the 243 HIV-positive patients (2.5\%) submitted to UDE in our service.

Five of these patients were male; patient age ranged from 29 to 46 years (mean: 37 years) The risk factors for HIV infection detected in patients with primary gastric NHL were sexual for four of the six cases and intravenous drug use for two patients. Median time between diagnosis of HIV and the appearance of NHL was 42 months (range: 8-96 months). Only three patients were using HAART before the diagnosis of NHL.

Median CD4 count was 140 cells $/ \mathrm{mm}^{3}$ (range: 55 to 326 cells $/ \mathrm{mm}^{3}$ ) and median viral load was 40,313 copies $/ \mathrm{mL}$ (range: 50 to $1,200,000$ copies $/ \mathrm{mL}$ ), measured in blood collected up to six months before UDE. The main complaints reported by the patients with NHL that led to the indication of UDE were epigastric pain in four cases, nausea and vomiting in two cases, and hematemesis in one case.

All six patients with gastric NHL presented lesions in the gastric region. Concomitant lesions in the fundus were found in three cases and there was involvement of the antrum in two cases. The UDE revealed a polypoid lesion in four cases (Figure 1a), ulcero-infiltrative lesions in two cases (Figure 1b), and ulcerated lesions in two cases (Figure 1c), with combined polypoid and ulcerated lesions observed in two cases (Figure 1d). Histology of the gastric lesions demonstrated B cell NHL in four cases and T cell NHL in two. 
Figure 1. Endoscopic view of the stomach showing a polypoid lesion (1a), an ulcero-infiltrative aspect (1b), an ulcerated lesion (1c), and a combined polypoid and ulcerated lesion (1d), compatible with non-Hodgkin's lymphoma.
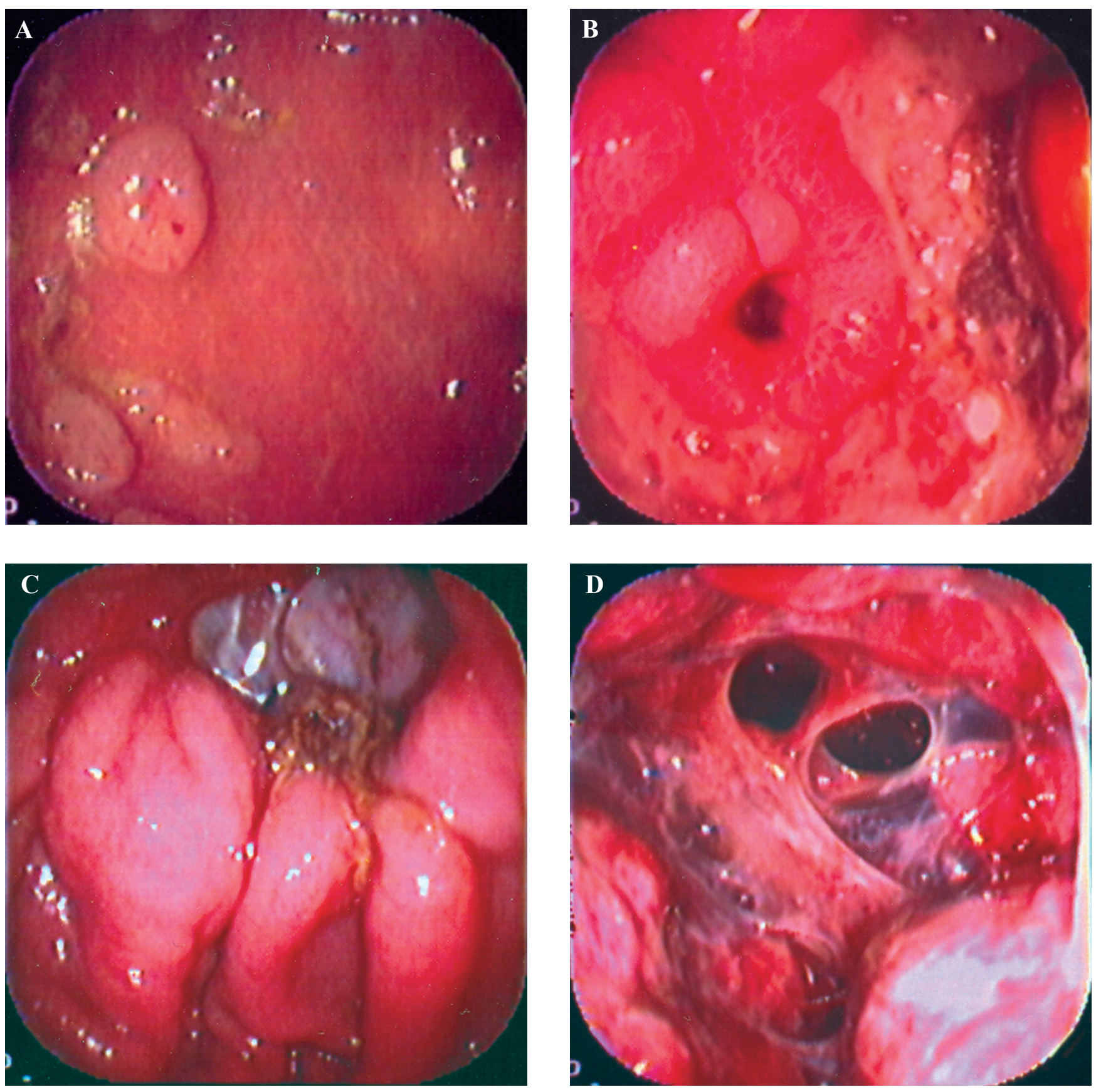

Five patients died of complications related to gastric lymphoma. The median survival time after the diagnosis of NHL was 185 days (range: 11 to 600 days). None of the patients who died had received specific chemotherapy. The most common causes of death were bacterial pneumonia in three cases and acute renal failure in two cases. Only one patient was still alive at the time we prepared this article, with a survival time of two years and 10 months. This patient had been submitted to three sessions of specific chemotherapy and continues to be clinically followed up, with no indication of cure of lymphoma thus far.

Lymphomas are common tumors in HIV-infected patients and, together with Kaposi's sarcoma, are responsible for approximately $95 \%$ of the neoplasias associated with AIDS $[6,8]$. Gastrointestinal tract (GIT) involvement by NHL is frequent in HIV-positive individuals, occurring in 15\% to $75 \%$ of all cases [1,2,9-13]. In this population, the GIT sites most frequently involved are the stomach ( $24 \%$ of cases), the small bowel ( $10 \%$ of cases), and the colon and rectum ( $7 \%$ of cases) $[2,5,6]$. The frequency distribution of GIT involvement by NHL in immunocompetent patients is similar, even more frequent in 
the stomach ( $50 \%$ to $80 \%$ of cases) and rarely affecting the small intestine, colon and perianal region $[2,5,14]$. In our study, among the $243 \mathrm{HIV}$-positive patients evaluated by UDE, six $(2.5 \%)$ had primary gastric NHL. All six patients had involvement of the gastric body, with involvement of the fundus in three cases and also of the antrum in two cases.

Involvement of the gastrointestinal tract by NHL frequently causes specific symptoms, the most common being abdominal pain, weight loss, and gastrointestinal bleeding. In our series, the main complaints of the patients were epigastric pain, nausea and vomiting. Hematemesis occurred in only one case.

AIDS-associated NHL are usually high-grade B-cell lymphomas; most of them are of extranodal origin $[1,2]$. Our histological findings revealed B cell NHL in four of the six cases and T cell NHL in two cases.

There are reports that the prognosis of gastrointestinal NHL is poor in patients with AIDS, with a survival of approximately six months $[1,13,15]$. We found a similar mean survival of about 185 days. A combination of chemotherapeutic agents is the treatment of choice for NHL. However, the rate of response to chemotherapy is normally low, usually less than $40 \%[2,16,17]$.

The presence of high CD4 counts and of polyclonal lymphomas, and the absence of Epstein-Bar virus infection and of AIDS-defining disease before diagnosis are associated with improved survival of these patients [2,10,11,16-19]. We conclude that NHL is a common complication occurring in the late phase of HIV infection, with a high frequency of stomach involvement. Despite all the advances in diagnosis and therapy, the occurrence of primary gastrointestinal NHL associated with HIV has been associated with reduced patient survival, being an important cause of AIDS-associated mortality.

\section{References}

1. Danzig J.B., Brandt L.J., Reinus J.F., Klein R.S. Gastrointestinal malignancy in patients with AIDS. Am J Gastroenterol 1991;86:715-8.

2. Heise W., Arastéh K., Mostertz P., et al. Malignant gastrointestinal Lymphomas in patients with AIDS. Digestion 1997;58:218-24.

3. Beck P., Gill M.J., Lloyd RS. HIV - associated Non - Hodgkin's Lymphoma of the gastrointestinal tract. Am J Gastroenterol 1996;91:2377-81.
4. Stebbing J., Gazzard B., Mandalia S., et al. Antiretroviral treatment regimens and immune parameters in the prevention of systemic AIDS - related Non - Hodgkin's Lymphoma. J Clin Oncol 2004;22:2177-83.

5. Radaszkiewicz T., Dragosics B., Bauer P. Gastrointestinal malignant lymphomas of the mucosa - associated lymphoid tissue: Factors relevant to prognosis. Gastroenterology 1992;102:1628-38.

6. Parente F., Rizzardini G., Cernuschi M., et al. Non - Hodgkin's Lymphoma and Aids: Frequency of gastrointestinal involvement in a large Italian series. Scand J Gastroenterol 1993;28:315-8.

7. Kirk O., Pedersen C., Cozzi-Lepri A., et al. Non - Hodgkin's Lymphoma in HIV - infected patients in the era of highly active antiretroviral therapy. Blood 2001;98:3406-12.

8. Levine A.M. Lymphoma in acquired immunodeficiency syndrome. Semin Oncol 1990;17:104-12.

9. Mitrou P.S., Serke M., Pohl C., et al. Mit der HIV - infektion assoziierte maligne lymphome. Dtsch med wochenschr 1991; $116: 1217-23$.

10. Kaplan L.D., Abrans D.L., Feigal E., et al. Aids - associated non Hodgkin's lymphoma in San Francisco. JAMA 1989;261:719-24.

11. Beral V., Peterman T., Berkelman R., et al. Aids-associated nonHodgkin's Lymphoma. Lancet 1991;337:805-9.

12. Pluda J.M., Yarchoan R., Jaffe E.S., et al. Development of nonHodgkin's lymphoma in a cohort of patients with severe human immumodeficiency virus (HIV) in long-term antiretroviral therapy. Ann Intern Med 1990;113:276-82.

13. Kaplan M.H., Susin M., Phawa S.G., et al. Neolplastic complications of HIV III infection. Am J Med 1987;82:389.

14. Sheperd N.A., Hall P.A., Coates P.J. Primary malignant lymphoma of the colon and rectum. A histopathological and immunohistochemical analysis of 45 cases with clinicopathological correlations. Histopatology 1988; $12: 235-52$.

15. Ahmed T., Wormser G.P., Stahl R.E., et al. Malignant lymphoma in a population at risk for acquired immune deficiency syndrome. Cancer 1987;60:719-23.

16. Gisselbrecht C., Oksenhendler E., Tirelli U., et al. Human immunodeficiency virus-related lymphomas treatment with intensive combination chemotherapy. Am J Med 1993;95:188-96.

17. Gérard L., Oksenhendler E., Lepage E., Gisselbrech C. Intensive chemotherapy for HIV- related non Hodgkin's lymphoma: Long-term follow-up and prognostic factors. In: Program and abstract: $11^{\text {th }}$ International Conference on Aids (Vancouver), 1996.

18. Tirelli U., Francheschi S., Carbone A. Malignant tumours in patients with HIV infection. BMJ 1994;308:1148-53.

19. Herndier B.G., Friedman S.L. Neoplasms of the gastrointestinal tract and hepatobiliary system in acquired immunodeficiency syndrome. Semin Liver Dis 1992;12:128-41. 